\title{
EFL Students' Reflections on Peer Scaffolding in Making a Collaborative Oral Presentation
}

\author{
Minh Hue Nguyen ${ }^{1}$ \\ ${ }^{1}$ Faculty of English Language Teacher Education, ULIS, Vietnam National University, Vietnam \\ Correspondence: Minh Hue Nguyen, Faculty of English Language Teacher Education, ULIS, Vietnam National \\ University, Hanoi, Vietnam. Tel: 61-469-147-242. E-mail: nguyenmhue@yahoo.com
}

Received: January 15, 2013 Accepted: January 31, 2013 Online Published: March 10, 2013

doi:10.5539/elt.v6n4p64 URL: http://dx.doi.org/10.5539/elt.v6n4p64

\begin{abstract}
Informed by sociocultural theory and previous research on peer scaffolding in second language (L2) learning, which largely focuses on collaborative writing in English as a second language (ESL) contexts, this study investigates the ways in which Vietnamese English as a foreign language (EFL) students provide peer scaffolding to each otherduring a collaborative presentation task and how they benefit from this experience. Data were collected from 12 participants through reflective reports and interviews. Content analysis of data suggests six categories of peer scaffolding behaviours among the students, namely workload sharing, pooling ideas and resources, technology support, peer feedback, support in answering the audience's questions, and affective support and the benefits that the students gained from them. The findings demonstrate that collaborative pair work creates learning conditions where peers provide mutual help, which supports previous research findings. The identified peer scaffolding behaviours also show important features suggested in the literature. Although peer scaffolding has been largely studied in L2 writing, it remains a new area of research in L2 speaking discourse. This study extends the literature to this under-researched area and offers a number of pedagogical and theoretical implications based on the findings.
\end{abstract}

Keywords: sociocultural theory, peer scaffolding, EFL, collaborative presentation

\section{Introduction}

In the last two decades, pair and group work has been widely used in many second language (L2) education contexts thanks to its pedagogical and theoretical values. From a pedagogical perspective, research has suggested that pair and group work has positive influence on learners' development (see Barnard, 2002; Barnard \& Campbell, 2005; Gibbons, 2002; De Guerrero \& Villamil, 2000; McDonough, 2004; Storch, 2002, 2005, 2007). From a theoretical point of view, collaborative learning is supported by a social constructivist perspective of learning, which is grounded in Vygotskian sociocultural theory of development (Vygotsky, 1978). This perspective sees learning as socially constructed through social interactions such as pair and group work.

Peer collaboration has also been largely studied in the L2 literature. This research has focused on both the process and the effectiveness of peer scaffolding. However, research on peer scaffolding in L2 writing within ESL contexts seems to currently constitute the largest volume of research in the area of peer scaffolding in L2 learning (De Guerrero \& Villamil, 2000; Storch, 2002, 2005, 2007; Shehadeh, 2011). There is a lack of focus on peer scaffolding in L2 speaking skills and other aspects of L2. In addition, most research on L2 scaffolding focuses on ESL settings rather than EFL contexts (see Barnard, 2002; Barnard \& Campbell, 2005; De Guerrero \& Villamil, 2000; Riazib \& Rezaii, 2011; Storch, 2002, 2005, 2007). In EFL settings, exposure to opportunities for L2 learning, especially speaking development, is usually less accessible in comparison with ESL settings, and peers appear to be an important source of learning for EFL learners. To support EFL teachers and learners in taking advantage of peer support in developing learners' English speaking ability, there needs to be more research data in this area to inform practice.

As an attempt to address the research gap discussed above, this study aims to understand the ways in which EFL students provide scaffolding to each other in completing a collaborative speaking presentation task and how they benefit from peer scaffolding through the course of the task. The 'scaffolding' metaphor has been largely discussed within a Vygotskian sociocultural framework. It is usually linked to Vygotsky's notion of the Zone of Proximal Development (ZPD). Serving as the theoretical framework of this study, the following sections discuss 
the ZPD and scaffolding.

\section{The Zone of Proximal Development}

The ZPD was initially proposed by Vygotsky (1978) to describe how cognitive growth occurred in children. Vygotsky (1978) defines the ZPD as "the distance between the actual development level as determined by independent problem solving and the level of potential development as determined through problem solving under adult guidance or in collaboration with more capable peers" (p. 86). Vygotsky (1978) argues that if we are to discover the actual relations of the development process to learning capacity, at least two developmental levels must be determined: the actual developmental level and the level of potential development. The former "defines functions that have already matured, that is, the end product of development" (p. 86). In other words, it is the child's ability to solve a problem without any assistance. The later "defines those functions that have not yet matured but are in the process of maturation, functions that will mature tomorrow but are currently in an embryonic state" (p. 86). Put it differently, those are functions that the child can perform when assisted.

There have been various interpretations of Vygotsky's notion of ZPD in the literature. Some researchers hold that interaction in the ZPD necessarily involves an expert and a novice (Lantolf, 2000; Nassaji \& Cumming, 2000). Some include equal peer collaboration such as pair or group work (Antón \& Dicamilla, 1999; Carmichael-Wong \& Vine, 2004; De Guerrero \& Villamil, 2000; Ohta, 2000; Tudge, 1990). Despite the different interpretations, all of the authors have agreed upon the basic components of the ZPD. That is, there is a task or a problem and a person who, with mediated assistance in the ZPD, can perform better than when unassisted.

\section{Scaffolding}

The scaffolding metaphor coined by Wood, Bruner and Ross (1976) is an important sociocultural concept. Wood et al. use it to describe the support provided by an expert or adult to a child or novice in one-on-one tutorial interactions in playful contexts. The adult let the child play with a task which was above the child's current ability but within his/her capacity for a while and only intervened when he/she got into difficulty and needed assistance. The adult's aim was to let the child "pace the task for himself as far as possible" (Wood et al., 1976, p. 92). According to Wood et al., scaffolding provided by an expert or adult "enables a child or novice to solve a problem, to carry out a task or to achieve a goal which would be beyond his unassisted efforts" (p. 90). They suggest six features of successful scaffolding: (a) recruiting the tutee's interest in the task; (b) reducing the degree of freedom in the task to make it manageable to the tutee; (c) maintaining goal direction; (d) marking critical features; (e) controlling frustration; and (f) modelling solutions to the task. They argue further that scaffolding may eventually result in "development of task competence by the learner at a pace that would outstrip his unassisted efforts" (p. 90). In the field of language learning, Van Lier (2004) notes six features of scaffolding:

1) Continuity: repeated occurrences over time, with variations connected to one another;

2) Contextual support: a safe but challenging environment, errors are expected and accepted as part of the learning process;

3) Intersubjectivity: mutual engagement and support, two minds thinking as one;

4) Contingency: the scaffolding support depends on learners' reactions, elements can be added, changed, deleted, repeated, etc.;

5) Handover/Takeover: there is an increasing role for the learner when skills and confidence increase;

6) Flow: communication between participants is not forced, but flows in a natural way.

Since its birth, the term scaffolding has been variedly interpreted and operationalized in various contexts such as formal classrooms, parent-child interaction, adult education, mainstream education as well as L2 education. The significance of scaffolding has been broadened to the extent that who provides scaffolding is no longer a question, as "expertise" rather than "experts" is becoming the focus (Carmichael-Wong \& Vine, 2004). Its use is no longer restricted to face-to-face interaction between an adult/expert and a child/novice. For example, many researchers have now considered peer collaboration (e.g. Barnard, 2002; De Guerrero\& Villamil, 2000; Riazi \& Rezaii, 2011; Shehadeh, 2011; Storch, 2007; Van Lier, 2004; Walqui, 2006) and interaction between a teacher and a classroom full of students as scaffolding (e.g. Davis \& Miyake, 2004; Many, Dewberry, Taylor, \& Coady, 2009).

Although Vygotsky never used the term scaffolding and Wood et al. (1976) did not base explicitly on Vygotsky's framework (Stone, 1993), the two concepts are often tied together. It is suggested that the theoretical basis of scaffolding "lies very much within Vygotskian framework" (Hammond \& Gibbons, 2001, p. 8) and that the 
Vygotskian framework is "at the heart of the concept of scaffolding" (Verenikina, 2003). According to Stone (1993), both ZPD and scaffolding concepts emphasize that the ability to perform a task develops through assisted performance. Similarly, Tabak (2004) states that helping learners through the ZPD to extend their actual development level is the major goal of scaffolding. Wells (1999) considers scaffolding as a way that the concept of working in the ZPD is operationalized. In other words, the dialogic nature of scaffolding, the significance of the sort of activity in which knowledge is co-constructed, and the roles of artefacts in mediating knowing make it a way of providing assistance needed for learners to progress through the ZPD (Barnard \& Campbell, 2005).

\section{Peer Scaffolding in Second Language Learning Research}

Research on peer scaffolding and L2 learning in particular has focused on two major themes, the effectiveness and mechanisms of peer scaffolding. In the effectiveness theme, peer scaffolding is often presented in L2 research as an effective way to foster L2 learners' development. Within the area of L2 writing, which represents the largest volume of L2 research on peer scaffolding, De Guerrero and Villamil (2000) observed a pair of ESL learners revising a written text and found evidence of development in both the student writer and the student reader. The student writer showed emerging self-regulation and grew into a more independent writer and reviser while the student reader developed aspects of L2 writing, revision, strategic assistance and collaboration. In a series of studies on peer scaffolding in collaborative ESL writing, Storch found a great number of instances showing development in L2 learners as a result of peer scaffolding. For example, Storch (2002) found evidence of transfer of knowledge as the members of the dyads co-constructed knowledge about language. Storch (2005) reported that peer-scaffolded learners produced shorter but better texts in terms of task completion, grammatical accuracy, and complexity in comparison with individual student writers. Similarly, Storch (2007) found opportunities for learners to use the target language for a range of functions that play an important role in language learning. Moreover, Shehadeh's study (2011) found that collaborative writing had a statistically significant effect on improving students' L2 writing in terms of content, organization, and vocabulary. The study shows that the peer scaffolding experience enhanced not only students' writing competence, but also their speaking ability and self-confidence.

In other L2 areas, Le's (2006) study on the use of group work in vocabulary learning in Vietnam finds that in both "unassisted" group work (5 students from the same class working together) and "assisted" group work (4 students from the same class working with 1 student from a higher class), students learnt new words, used collective memory and received help from other group members in learning and using the new words. However, the group assisted by a more capable peer used more target language in the discussion than the unassisted group. Similarly, Le's study (2007) shows that expert-novice group work created more learning opportunities than unassisted group work. Other researchers (e.g. Barnard, 2002; Barnard \& Campbell, 2005; Gibbons, 2002; McDonough, 2004) also report that L2 students working in pairs or groups can produce results that extend beyond their individual competence.

In comparison with effectiveness-focused studies on peer scaffolding, research in the mechanisms theme has been limited. However, this body of scholarship has some important contributions to the knowledge base about peer scaffolding behaviours. De Guerrero and Villamil (2000) found that while two ESL learners worked jointly in revising a written text, the reader displayed scaffolding behaviours that facilitated development, namely (a) recruiting and maintaining the writer's interest, (b) marking critical aspects or discrepancies in the writer's text, (c) explicitly instructing the writer on issues of grammar and mechanics, and (d) modelling. In addition, the reader also showed (a) willingness to influence the partner's actions, to keep the interaction going, and to accomplish goals, (b) efforts at making the task manageable for both and inducing solutions to textual problems, (c) promotion of understanding by focusing on what was not clear or discrepant and eliciting clarification or correction, and (d) ability to read his partner's cues and respond accordingly. These findings were supported by Riazi and Rezaii's (2011) recent study on peer scaffolding in ESL writing. Furthermore, studies by Storch (2002, 2005,2007 ) add some insights into the peer scaffolding mechanisms with the findings that during collaborative writing L2, learners are able to pool their linguistic resources and ideas, provide feedback, make suggestions and counter-suggestions, offer explanations, and repeat the suggestions made. The types of scaffolding behaviours reported in these studies were used to guide data analysis in this study.

The reviewed literature has important contributions to the field's understanding of peer scaffolding and L2 learners' development. However, this literature has largely focused on ESL contexts (see Barnard, 2002; Barnard \& Campbell, 2005; De Guerrero \& Villamil, 2000; Riazi \& Rezaii, 2011; Storch, 2002, 2005, 2007) rather than EFL settings. Moreover, most of the existing research investigates peer scaffolding in collaborative writing and other aspects of L2 rather than L2 speaking. To the best of my knowledge, no research has been done on peer scaffolding in making an oral presentation in L2, especially in an EFL context. Since research findings about 
peer scaffolding in ESL writing and other areas might not be universally and easily generalizable to peer scaffolding in making L2 presentations in EFL contexts, there is a great need to address this gap. The present study is an attempt to probe into this new area of inquiry. It investigates the ways scaffolding is provided by university EFL students in making a collaborative presentation and how they benefit from peer scaffolding to develop through their ZPD. The following questions framed this investigation:

1) In what ways do university EFL students provide scaffolding to each other in making a collaborative presentation?

2) How do the students benefit from the peer scaffolding experience?

\section{Setting and Participants}

The setting of this study is a university in Vietnam. The university offers a four-year BA program of EnglishLanguage Teaching. The study was conducted during a third-year English speaking course which aimed to develop the students' English speaking skills. The course lasted 15 weeks. Every two weeks the class followed a predetermined theme. Except for week 8, which is designed for mid-term exams, there are seven themes during the course. The students were divided into pairs to prepare for their collaborative ten-minute presentation. After the first two weeks for preparation, from the third week, the students took turns delivering the presentation as a course assignment in pairs each week. The presentations followed the themes and had been scheduled from the beginning of the course. One week after the presentation, the students submitted to the teacher a written report in which they reflected on their preparation, delivery and evaluation of the presentation. After informed and voluntary consent was obtained, six pairs of third-year TESOL students in their early twenties were selected as the participants of this study. They had between ten and 13 years of English learning experience and knew each other well because they had been studying together in the BA program for three years.

\section{Method}

In order to answer the research questions, qualitative data were collected from student reflective reports and semi-structured interviews. As the students were at a high level of proficiency, English was used in self-reflections and interviews. Most previous research on peer scaffolding uses observation of peers' direct interaction to gather data about the ways peers scaffold each other. However, in this study most of the time the participants prepared the presentation outside the classroom and over a few days to a few weeks. Therefore, reflective reports and interviews were considered more suitable methods to gain information about the peer scaffolding experience than researcher observation.

After the presentation, each student produced a written reflective report on their preparation and delivery of the collaborative presentation as a requirement of the assignment. The students were instructed to reflect particularly on how they worked together in doing the task and how the collaborative experience helped them to develop. Their reflective reports were analysed in order to gain insights into the ways they provided scaffolding to each other. Individual interviews were conducted after the presentations to elicit in-depth information about instances of peer scaffolding and how peer scaffolding helped them to develop through the task. This allowed me to elicit the participants' reflection on and interpretation of their experience in scaffolding each other and find the answers to the research questions.

\section{Findings and Discussion}

All data from students' reflective reports and interviews were coded and analysed qualitatively using content analysis. Data were first coded deductively against the types of scaffolding behaviours and effects found in previous research. In addition, I was conscious that this study is among the first to look into peer scaffolding in an EFL oral presentation, a type of task that previous research on peer scaffolding has not investigated. Therefore, I also analysed the data inductively to allow for new themes that correspond to the nature of the task, the participants and the setting to reveal naturally.

Analysis of the data shows a range of ways in which the students provided scaffolding to each other in preparing for and delivering the collaborative presentation. It also reveals the benefits that the participants gained from the peer scaffolding experience. The findings are presented and discussed below with excerpts from the students' interviews and reflections. All students' real names are replaced with pseudonyms. Discussion of results is related to the literature.

\subsection{Workload Sharing for Effective Preparation}

One of the most frequently acknowledged kinds of peer support identified in the data is the sharing of workload between group members. Consider the students' comments on their work division when preparing for the 
presentation:

We worked together to complete the task... These tasks are divided to ensure the equality among peers.... About designing the slide show, each made the slides which contain her parts as we thought that one will know more exactly what should or shouldn't be on the slides during her speech than anybody else. After that, I am responsible for combining all of them, formatting and adding the animations for the whole slides. For the video and images, I am in charge of making and editing the video while [Ly] works hard on finding the suitable images for illustrating the content of the presentation. Overall, task division is quite equal and effective for both members of our group. We saved a lot of time and effort in comparison to individual working. (Hien, reflective report)

When preparing for this, members in our group shared the works and helped each other a lot from consulting web pages for information, searching for pictures to preparing slides and listening to others' rehearsal. (Diep, interview)

It can be seen from the excerpts above that the students mutually engaged in preparing the presentation. This helped them to save time and effort while still enabled them to achieve their common goals. This is in line with the intersubjectivity feature of scaffolding (Van Lier, 2004) because members of each pairs shared responsibilities in doing the task. They interacted with each other and their minds worked on one common task. Interestingly, workload sharing among peers was not simply dividing the work equally. Peers reportedly took into account group members' strengths when they shared the task. Consider the following excerpt:

We shared the work equally and suitably to each member's strength... I am always trusted to do the content, not the technology; therefore my partner was in charge of technology like cut films, clips, formatting PPT.... That's why we had fascinating slides and interesting and appropriate tracks of films. (Nga, reflective report)

Here the two students were able to provide contingent scaffolding to each other, which is congruous with the findings of previous studies (e.g., Carmichael-Wong and Vine, 2004; Lantolf and Aljaafreh, 1995; Van Lier, 2004). It can be inferred from the extract that Nga is good at "the content" but not "the technology", which might be her partner's strength. When the students were in charge of the areas that they are good at, the work seemed easy and more effective for both members. This finding lends support to De Guerrero and Villamil's (2000) conclusion that in mutually scaffolding each other, students showed efforts at making the task manageable for both.

\subsection{Pooling of Ideas and Resources for Better Content Knowledge and an Informative Presentation}

The data reveal pooling of ideas and resources as another peer scaffolding behaviour among the participants. A similar findings also reported by Storch (2005). In the present study, four out of 12 students noted that their peers' contribution of ideas was among the most important types of peer support they received. Nhu and Mai described how they supported each other in choosing a topic for their presentation and how it worked for them.

When we had to pick up a topic for an explanatory presentation, about which we had little understanding, we got stuck. But then thanks to the contribution of many ideas from peer, we could pick up a nice topic...

The knowledge of each individual is limited; hence without discussion in group, we could never have thought of such an interesting topic. (Nhu and Mai, reflective report)

Clearly, two heads is better than one in this case as it enabled the pairs to come up with a better topic than either of them could individually have. A similar comment was made by An. She added that her partner not only contributed ideas for the presentation but also gave her feedback on the ideas that she put forward:

The contribution of ideas is the greatest assistance I received from my peer. She also gave comments on my choice of ideas and showed me how to revise it. (An, interview)

Besides idea support, two other students also noted that their peers provided them with reference materials and sources of materials. Hien described how her partner sought and shared with her materials about their presentation topic of Thai culture:

She has tried hard in mailing our teacher of Thai to ask for more suggestions and found a lot of materials by herself then she sent them to me. Together with what I have found, her materials gave me a deep vision of Thai culture. (Hien, interview)

Clearly, with her partner's sharing of materials, Hien developed a deep content knowledge of the presentation topic. Pooling materials was also in the form of sending web links to each other, as Diep noted:

I can't find any on the history information of the machine we work on, [Thu] sent me some links for 
reference. That is what I think necessary to have a good presentation. (Diep, interview)

The students' scaffolding shows some features that have been reported in the literature including contingency (Carmichael-Wong and Vine, 2004) and mediation (Tabak, 2004). For example, Thu's scaffolding for Diep appears to be contingent on Diep's need of information about the presentation topic. The students' scaffolding for their peers was also mediated by artefacts such as reference materials and the Internet.

\subsection{Technology Support for Improved Technical Skills and an Effectively Illustrated Presentation}

The students in this study all used power point presentations. Therefore, technology was one of the areas in which they provided scaffolding to each other. Chung and Hien were not good at technical matters, and they received help from their partners in this area:

She helped me with what I'm not good at, for example, making slides. (Chung, interview)

When I had troubles in creating some charts or making a clip to illustrate my contents, my partner showed me the way to do it. (Hien, interview)

Chung's partner provided help by doing the task for her. However, the case of Hien is different in that her partner opted to show her how to make charts and a video clip rather than doing it for her. Both Chung and Hien's partners offered scaffolding that is contingent on their peers' difficulty areas, but Hien might have experienced more learning opportunities as she actually learnt new technical skills from her partner.

Similarly, Mi also noted that she had difficulty in creating a video clip for the presentation. Her partner, Yen, who was considered an IT expert, took over this task for her. In return, Mi offered scaffolding by improving the slides and video clip created by Yen. Let's consider the following responses from Mi and Yen:

[Yen]... a IT pro... made a video clip for the presentation, which is a challenge for me at that time. (Mi, interview)

She helped me with the technical matters by brushing up our slides and clips when I had finished the rough part. (Yen, interview)

The two excerpts show that Mi and Yen provided mutual scaffolding to each other. This scaffolding exhibits the principles of intersubjectivity and contingency as described by Van Lier (2004) as the peers worked collaboratively on the task and helped each other to overcome their weaknesses.

\subsection{Feedback for Language Development and Better Delivery of Speech}

Feedback is the type of peer scaffolding noted by most of the students, and it is also the type they highly appreciated. Let's consider an example of how they mutually engaged in giving comments on their shared work, helped each other to improve their pronunciation and polish their slides:

[Len] had an overall look at the final product and pointed out some flaws so that we could fix them together.... We spent the morning of the presenting day rehearsing, helping each other correct some pronunciation mistakes or shorten some unnecessary parts. (Nga, reflective report)

Len also described how her peer provided feedback during their rehearsal to keep her speaking at an appropriate pace:

I always felt being rushed because of the limited time... I spoke very fast [during the rehearsals]. She said that I should speak slowly, because she realized the photos or pictures had to "fly" to be suited to my speed. Besides, [Nga] was careful to check the information to be accurate. (Len, reflective report)

Two students also reported how peer scaffolding helped them to improve pronunciation and achieve coherence in the presentation by using transitional sentences:

When preparing for the presentation, we seemed to do every step together, thus we had proper comments on each other's part. When rehearing, we helped each other to correct pronunciation mistakes and making up transitional sentences between different parts of the presentation.... (Mi and Yen, reflective report)

The students appeared to be actively involved in marking critical features in each other's performance and in their common work, which is one of the features of successful scaffolding suggested by Wood et al. (1976). Clearly, the students have offered feedback to each other in many aspects of the presentation task, including the content, pronunciation, speaking pace, coherence, and so on. Furthermore, they were also engaged in making suggestions for their peers to resolve the discrepancies. This finding lends support to the result of Storch (2007).

7.5 Support in Answering the Audience's Questions, Saving Each Other and Satisfying the Audience

Three out of 12 students noted that they received support from their partners in the question and answer session 
that followed the presentation. The support ranges from complete takeover of the answer to partial contribution to the answer. Nhu reflected back on her peer's scaffolding in answering the audience's questions:

In conducting a presentation on difference between Vietnamese and English eating manners, I was asked to describe in detail which utensil is used for which purpose. I was unprepared for this question and went speechless. But then my partner raised her voice and supported me with her comprehensible knowledge on this issue. I felt really grateful and relieved. (Nhu, interview)

The scaffolding provided to Nhu was very simultaneous and contingent on her needs at the time. Apparently, when Nhu had nothing to say in response to the question, the support saved her on the spot and contributed to the pair's task completion. Mi also acknowledged her peer's support in satisfying the audience's question:

When dealing with audience's questions, she also contributed to my answers so that our answers could satisfy the classmates. (Mi, interview)

7.6 Affective Support for Enduring Task Engagement, Rapport, Self-Confidence and a Sense of Safety and Success

Another important form of peer scaffolding acknowledged by many of the students is affective support. At times Hien seemed to lack energy and motivation to complete her tasks, and support from her partner appeared to be very helpful at these times. Hien wrote:

When I feel exhausted because of a lot of things to do, observing my peers still working tirelessly, I try again. I don't want to give up any more. I said to my peer that there are a lot of assignments to finish besides group presentation between her and me. She coaxes me with some kind words like: "don't worry", "everything will be alright after all"... I am back to optimistic life again. Thanks for that. (Hien, reflective report)

Here there are two sources of affective support for Hien, one from watching her peers working hard and the other from the kind words given by her partner. While the first source of support was not provided intentionally by the peers, the second source was really responsive and contingent on Hien's reactions to assignments. It is in line with the "recruiting the tutee's interest in the task" and somewhat "controlling frustration" features of effective scaffolding (Wood et al., 1976). Ly provided further comments on the mutual affective support between her and Hien:

Spiritual assistance, if counted, is worth being mentioned as well. Since work load is very much of a buzzword to us all, and a group presentation is like an additional big load, we have the stress level raised. For this, mutual encouragement and sympathy become a critical element.... In the meantime, mutual encouragement and frequent meeting occasion in the process of preparation are what ties the emotional knot among us. (Ly, reflective report)

Some other students also noted that working in pairs created a safe, friendly and comfortable learning environment, which not only lifted their work burden but also helped to boost their confidence, especially when they were on stage delivering the presentation. This lends support to Shehadeh's (2011) findings on the role of peer scaffolding in improving students' self-confidence.Consider the following comments with regards to these aspects of peer scaffolding:

Working in pair brings me a feeling of more safety than working individually. That's because my peer helps me deal with audience's questions. The cooperation contributes greatly to the success of the presentation. My partner's help on the stage could raise my confidence. (Mi, interview)

She well-cooperated with me during the performance in small friendly conversations, which made me feel confident and comfortable. (Yen, interview)

Moreover, Chung and Hien noted that their partners also supported them by reminding them of the deadline and helping them to overcome procrastination. This form of scaffolding is helpful in maintaining the students' goal direction (Wood et al., 1976).

\section{Conclusion and Implications}

Informed by a sociocultural perspective and previous research on peer scaffolding in L2 learning, I began the study to answer the research questions: In what ways do university EFL students scaffold each other in making a collaborative presentation? And How do the students benefit from the peer scaffolding experience? Analysis of 12 Vietnamese EFL students' interviews and reflective reports showed a range of peer scaffolding behaviours, including workload sharing, pooling of ideas and resources, technology support, peer feedback, support in answering the audience's questions, and affective support. The students' scaffolding behaviours showed 
important features that have been observed in past research. The findings of this study lend support to some types of scaffolding behaviours found in previous research such as workload sharing (i.e. efforts at making the task manageable for both (De Guerrero \& Villamil, 2000)), pooling of ideas and resources, and feedback (Storch, 2002, 2005, 2007). Besides, the study also found three new types of scaffolding mechanisms namely technology support, support in answering the audience's questions, and affective support. This is probably because the study is one of the first to look at peer scaffolding in making an L2 oral presentation, and these new types of scaffolding behaviours are typical for this kind of task.

In this study, peer scaffolding was beneficial and highly valued by the participants. As demonstrated by the data, it helped them to overcome many challenges in the task such as lack of ideas, shortages of materials, limited technology skills and content knowledge, and develop knowledge, skills (e.g. pronunciation, computer skills and presentation skills), motivation and confidence needed for completing the task. The collaborative experience also provided them opportunity to build rapport with each other. Generally, peer support enabled the students to achieve higher than they could do in an individual presentation and progress through their ZPD. These findings on the benefits of peer scaffolding support some of the previous research such as improvement in the content and organisation of their shared work (Shehadeh, 2011) and development of language ability (Storch, 2002).

These findings have important pedagogical and theoretical implications for the field of L2 education. Pedagogically, the findings support the use of collaborative pairs in oral presentation tasks. Moreover, in order for the students to benefit the most from their peers, when assigning students into groups teachers could consider their strengths and weaknesses so that each student has certain areas of expertise that the other can benefit from. From a theoretical perspective, the study lends support to a sociocultural perspective on language learning, which sees collaborative interactions as an in important source of learning. More importantly, it adds to previous attempts to extend the significance of sociocultural scaffolding and the ZPD from expert/novice relationship to collaborative relationship. Furthermore, this study is among the first attempts to look into peer scaffolding during an EFL collaborative presentation task, which contributes to the extension of research base from written discourse in ESL contexts to a more complicated task of making an oral presentation in an EFL setting.

Finally, as this study is one of the first to investigate EFL learners' scaffolding in a collaborative presentation, more research needs to be done in this area to allow for comparisons and generalizations of results. Future research might involve a larger sample in other EFL contexts and use other research methods such as observation, learner diaries and focus group interviews to collect more insightful data. Further research might also extend its scope to establish the relationship between peer scaffolding in L2 collaborative presentation and students' cognitive and metacognitive development.

\section{References}

Antón, M., \& Dicamilla, F. J. (1999). Socio-cognitive functions of L1 collaborative interaction in the L2 classroom. The Modern Language Journal, 83(2), 233-247. http://dx.doi.org/10.1111/0026-7902.00018

Barnard, R. (2002). Peer tutoring in the primary classroom: A sociocultural interpretation of classroom interaction. New Zealand Journal of Educational Studies, 37(1), 57-72.

Barnard, R., \& Campbell, L. (2005). Sociocultural theory and the teaching of process writing: The scaffolding of learning in a university context. The TESOLANZ Journal, 13, 76-88.

Carmichael-Wong, S., \& Vine, E. W. (2004). Peer-scaffolding or collaborative problem-solving?: A data-based study of three learners' experience. New Zealand Studies in Applied Linguistics, 10(2), 39-60.

Chaiklin, S. (2003). The zone of proximal development in Vygotsky's analysis of learning and instruction. In A. Kozulin, B. Gindis, V. S. Ageyev, \& S. M. Miller (Eds.), Vygotsky's educational theory in cultural context (pp. 39-64). Cambridge: Cambridge University Press. http://dx.doi.org/10.1017/CBO9780511840975.004

Davis, E. A., \& Miyake, N. (2004). Explorations of scaffolding in complex classroom systems. The Journal of the Learning Sciences, 13(3), 265-272. http://dx.doi.org/10.1207/s15327809jls1303_1

De Guerrero, M. C. M., \& Villamil, O. S. (2000). Activating the ZPD: Mutual scaffolding in L2 peer revision. The Modern Language Journal, 84(i), 51-68. http://dx.doi.org/10.1111/0026-7902.00052

Gibbons, P. (2002). Scaffolding language, scaffolding learning: Teaching second language learners in the mainstream classroom. Portsmouth, NH: Heinemann.

Hammond, J., \& Gibbons, P. (2001). What is scaffolding? In J. Hammond (Ed.), Scaffolding Teaching and Learning in Language and Literacy Education (pp. 1-14). Newtown, N.S.W: PETA. 
Lantolf, J. P. (2000). Introducing sociocultural theory. In J. P. Lantolf (Ed.), Sociocultural theory and second language learning (pp. 1-26). Oxford: Oxford University Press.

Lantolf, J. P., \& Aljaafreh, A. (1995). Second language learning in the zone of proximal development: A revolutionary experience. International Journal of Educational Research, 23(7), 619-632. http://dx.doi.org/10.1016/0883-0355(96)80441-1

Lantolf, J. P., \& Appel, G. (1994). Theoretical framework: An introduction to Vygotskian approaches to second language research. In J. P. Lantolf, \& G. Appel (Eds.), Vygotskian approaches to second language research (pp. 1-32). Norwood, N.J.: Ablex Pub. Corp.

Le, P. H. H. (2006). Mediation through the first language: A sociocultural study of group work in Vietnam. RELC Journal, 37(1), 105-121. http://dx.doi.org/10.1177/0033688206063477

Le, P. H. H. (2007). The more knowledgeable peer, target language use, and group participation. The Canadian Modern Language Review, 64(2), 333-354.

Many, J. E., Dewberry, D., Taylor, D. L., \& Coady, K. (2009). Profiles of three preservice ESOL teachers' development of instructional scaffolding. Reading Psychology, 30(2), 148-174. http://dx.doi.org/10.1080/02702710802275256

McDonough, K. (2004). Learner-learner interaction during pair and small group activities in a Thai EFL context. System, 32(2), 207-224. http://dx.doi.org/10.1016/j.system.2004.01.003

Nassaji, H., \& Cumming, A. (2000). What's in a ZPD? A case study of a young ESL student and teacher interacting through dialogue journals. Language Teaching Research, 4(2), 95-121.

Nassaji, H., \& Swain, M. (2000). A Vygotskian perspective on corrective feedback in L2: The effect of random versus negotiated help on the learning of English articles. Language Awareness, 9(1), 34-51. http://dx.doi.org/10.1080/09658410008667135

Ohta, A. S. (2000). Rethinking interaction in SLA: Developmentally appropriate assistance in the zone of proximal development and the acquisition of L2 grammar. In J. P. Lantolf (Ed.), Sociocultural theory and second language learning (pp. 51-78). Oxford: Oxford University Press.

Riazi, M., \& Rezaii, M. (2011). Teacher- and peer-scaffolding behaviors: Effects on EFL students' writing improvement. In A. Feryok (Ed.), CLESOL 2010: Proceedings of the 12th National Conference for Community Languages and ESOL (pp. 55-63).

Shehadeh, A. (2011). Effects and student perceptions of collaborative writing in L2. Journal of Second Language Writing, 20, 286-305. http://dx.doi.org/10.1016/j.jslw.2011.05.010

Stone, C. A. (1993). What is missing in the metaphor of scaffolding? In E. A. Forman, N. Minick, \& C. A. Stone (Eds.), Context for Learning (pp. 169-182). Oxford: Oxford University Press.

Storch, N. (2002). Patterns of interaction in L2 pair work. Language Learning, 52(1), 119-158. http://dx.doi.org/10.1111/1467-9922.00179

Storch, N. (2005). Collaborative writing: Product, process, and students' reflections. Journal of Second Language Writing, 14, 153-173. http://dx.doi.org/10.1016/j.jslw.2005.05.002

Storch, N. (2007). Investigating the merits of pair work on a text editing task in ESL classes. Language Teaching Research, 11(2), 143-159. http://dx.doi.org/10.1177/1362168807074600

Tabak, I. (2004). Synergy: A complement to emerging patterns of distributed scaffolding. The Journal of the Learning Sciences, 13(3), 305-335. http://dx.doi.org/10.1207/s15327809j1s1303_3

Tudge, J. (1990). Vygotsky, the zone of proximal development, and peer collaboration: Implications for classroom practice. In L. C. Moll (Ed.), Vygotsky and education: instructional implications and applications of sociohistorical psychology (pp. 155-172). Cambridge: Cambridge University Press. http://dx.doi.org/10.1017/CBO9781139173674.008

Van Lier, L. (2004). The ecology and semiotics of language learning. Dordrecht: Kluwer Academic Press. http://dx.doi.org/10.1007/1-4020-7912-5

Verenikina, I. (2003). Understanding scaffolding and the ZPD in educational research. Paper presented at the NZARE AARE Joint Conference, Auckland.

Vygotsky, L. S. (1978). Mind in society: The development of higher psychological processes. Masachusetts: Harvard University Press. 
Walqui, A. (2006). Scaffolding instruction for English language learners: A conceptual framework. The International Journal of Bilingual Education and Bilingualism, 9(2), 159-180. http://dx.doi.org/10.1080/13670050608668639

Wells, G. (1999). Using L1 to master L2: A response to Antón and DiCamilla's "Socio-cognitive functions of L1 collaborative interaction in the L2 classroom". The Modern Language Journal, 83(2), 248-254. http://dx.doi.org/10.1111/0026-7902.00019

Wood, D., Bruner, J. S., \& Ross, G. (1976). The role of tutoring in problem solving. Journal of Child Psychology and Psychiatry, 17, 89-100. http://dx.doi.org/10.1111/j.1469-7610.1976.tb00381.x 